\title{
Black pus from a worn-out elbow arthroplasty
}

\author{
Marjan Wouthuyzen-Bakker ${ }^{1}$ and Alexander L. Boerboom ${ }^{2}$ \\ ${ }^{1}$ Department of Medical Microbiology and Infection Prevention, University of Groningen, \\ University Medical Center Groningen, Groningen, the Netherlands \\ ${ }^{2}$ Department of Orthopaedic Surgery, University of Groningen, University Medical Center Groningen, \\ Groningen, the Netherlands
}

Correspondence: Marjan Wouthuyzen-Bakker (m.wouthuyzen-bakker@umcg.nl)

Received: 19 December 2021 - Revised: 23 January 2022 - Accepted: 24 January 2022 - Published: 7 February 2022

\section{Clinical picture}

A 64-year-old woman with a medical history of rheumatoid arthritis and multiple joint prostheses presented to our hospital. She had been experiencing pain and a greyish swelling in her left elbow, which had undergone arthroplasty 25 years prior. The swelling eventually opened and drained black metal-like pus (Fig. 1). The prosthesis (a Kudo type 15) was extracted in a two-stage exchange procedure in which darkgrey debris and necrosis were observed (Fig. 2). Cultures revealed the presence of a polymicrobial periprosthetic joint infection (PJI). The patient was treated with amoxicillin and clavulanic acid for 6 weeks and had a flail elbow for 1 year. Finally she received a successful revision arthroplasty with a Coonrad-Morrey elbow prosthesis.

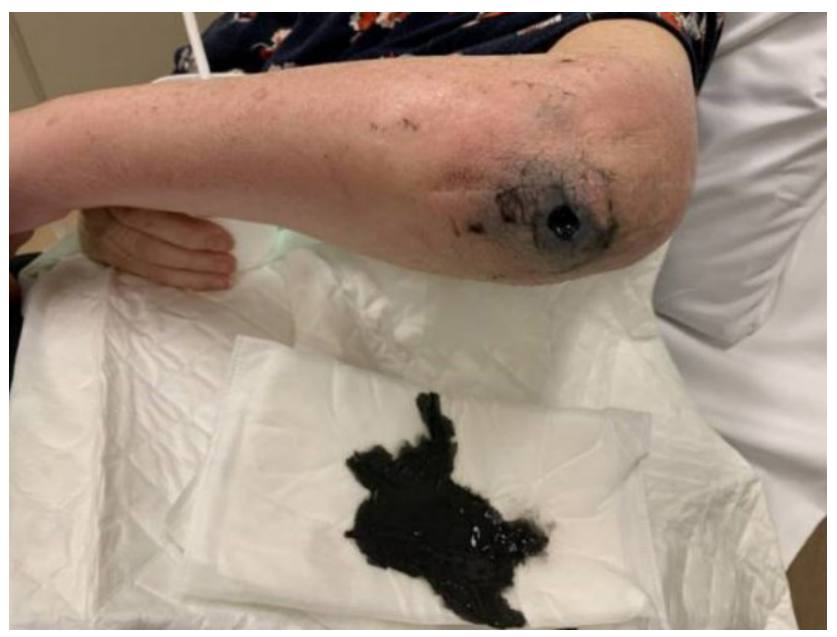

Figure 1. Draining sinus with black pus.

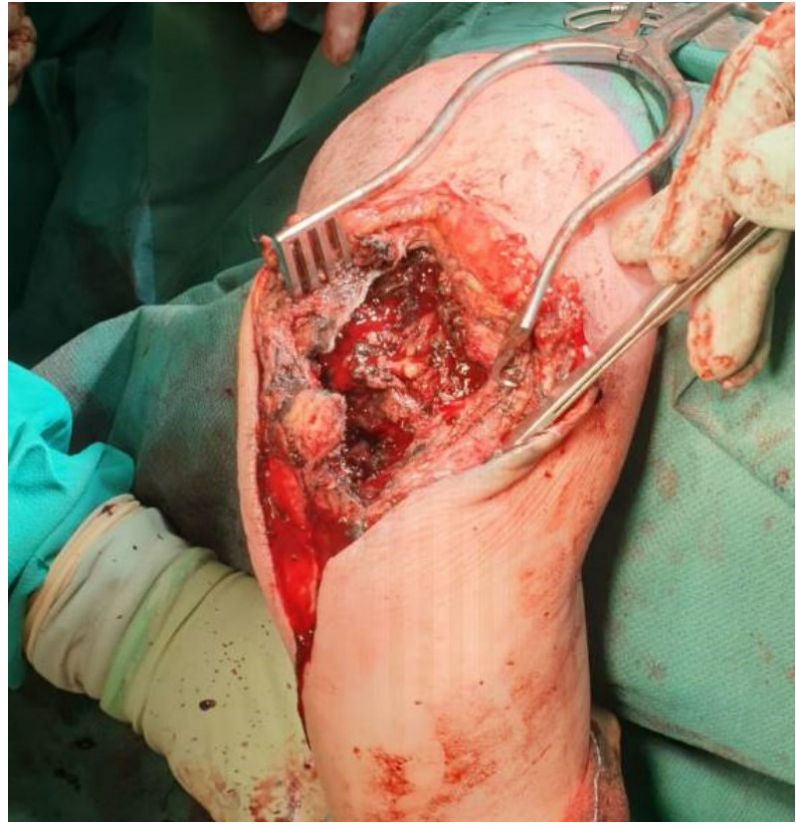

Figure 2. Grey-coloured synovitis and necrosis caused by metallic wear debris due to the release of cobalt, chromium, and titanium particles (Brinkman et al., 2007).

\section{Conclusion}

A worn-out elbow prosthesis causes polyethylene wear and, eventually, severe metallosis when not revised in a timely manner. Damage to the joint, surrounding bone, and soft tissue results in an impaired local immunity and sinus to the skin. These factors make the prosthetic joint more prone to subsequent polymicrobial infection (Barba et al., 2015; Tai et al., 2021). 
Data availability. No data sets were used in this article.

Author contributions. MWB and AL contributed equally in writing the text.

Competing interests. At least one of the (co-)authors is a member of the editorial board of Journal of Bone and Joint Infection. The peer-review process was guided by an independent editor, and the authors also have no other competing interests to declare.

Disclaimer. Publisher's note: Copernicus Publications remains neutral with regard to jurisdictional claims in published maps and institutional affiliations.

Acknowledgements. The authors would like to thank the patient for her willingness to publish her pictures.

Review statement. This paper was edited by Parham Sendi and reviewed by two anonymous referees.

\section{References}

Barba, T., Wach, J., Lustig, S., Laurent, F., DevouassouxShisheboran, M., Valour, F., Chidiac, C., Ferry, T., and Lyon BJI Study Group: Metallosis-associated prosthetic joint infection, Med. Mal. Infect., 11-12, 484-487, 2015.

Brinkman, J. M., de Vos, M. J., and Eygendaal, D.: Failure mechanisms in uncemented Kudo type 5 elbow prosthesis in patients with rheumatoid arthritis, Acta Orthop., 78, 263-270, 2007.

Tai, D. B. G., Patel, R., Abdel, M. P., Berbari, E. F., and Tande, A. J.: Microbiology of hip and knee periprosthetic joint infections: a database study, Clin. Microbiol. Infect., 28, P255-259, https://doi.org/10.1016/j.cmi.2021.06.006, 2021. 